\title{
AN INTEGRATED STUDY OF THE GRAYBURG/SAN ANDRES RESERVOIR, FOSTER AND SOUTH COWDEN FIELDS, ECTOR COUNTY, TEXAS
}

Cooperative Agreement No.: DE-FC22-93BC14982--13

Contractor Name and Address: Laguna Petroleum Corporation 10003 N. Big Spring

P. O. Box 2758

Midland, TX 79702

Date of Report: May 28, 1997

Anticipated Completion Date: February 2, 1998

Government Award for Current Fiscal Year: \$649,100

Principal Investigators: Robert C. Trentham, DGS

Richard Weinbrandt, Ph.D. P.E.

William Robertson, M.S.

Reporting Period: First Quarter 1997, January - March 1997 


\section{Disclaimer}

This report was prepared as an account of work sponsored by an agency of the United States Government. Neither the United States Government nor any agency thereof, nor any of their employees, makes any warranty, express or implied, or assumes any legal liability or responsibility for the accuracy, completeness, or usefulness of any information, apparatus, product, or process disclosed, or represents that its use would not infringe privately owned rights. Reference herein to any specific commercial product, process, or service by trade

name, trademark, manufacturer, or otherwise does not necessarily constitute or imply its endorsement, recommendation, or favoring by the United States Government or any agency thereof. The views and opinions of authors expressed herein do not necessarily state or reflect those of the United States Government or any agency thereof. 


\section{OBJECTIVES}

\section{Geophysical Objectives}

The goals of work done this quarter were 1) to analyze the preliminary seismic inversion model for the Grayburg $A, B$, and $C$ sequences and the upper San Andres formation; 2) modify the inversion model to improve its accuracy and to include the deeper Holt Formation; and 3) test various rock property quantities against the improved model and other seismic attributes using refined analysis boundaries. A satisfactory inversion model and porosity analysis remains to be accomplished, but much has been learned about the modeling and analysis processes. Qualitative comparison of sonic logs with the inversion model traces in profile view shows great similarity and success is being made toward good quantitative results.

\section{Geologic Objectives}

Integrate the results of the Witcher \#12 new drill into the reservoir model derived from modern logs, core descriptions, core analyses and seismic. Working with other team members to implement a completion technique designed to double the fracture length in the lower Grayburg and San Andres. Continue to develop a usable seismic velocity/log porosity transform. Continue evaluation of effectiveness of recent completions utilizing water analyses.

\section{Engineering Objectives}

To continue to enhance production by developing completion techniques designed for specific zones, areas, and problems. Test the seismic generated porosity maps in the simulation. Continue to improve the waterflood and injection system. 


\section{SEISMIC}

Several Definitions:

seismic inversion modeling - a process of converting seismic ampliude data from sinusoidal traces containing a seismic wavelet to blocky, log-like traces with wavelet complexity removed, modeled directly from the wiggle traces using parameters that are geologically significant; the example to the right shows seismic traces and the modeled blocky inversion trace; phase shifts have been applied to demonstrate the effect on the inversion result

analysis boundaries - surfaces defined by log correlations, which may or may not be seismic reflection horizons, positioned in seismic time in order to measure seismic characteristics for that very specific zone; they commonly cross changes in rock properties

cross-plot - a graph generated by the Vest 3DSEIS interpretation software showing the relationship of some seismic data property and a rock property (for example, seismic velocity vs. rock porosity); a line of best fit is calculated, the slope of which can be used to convert data from seismic property values into log property values

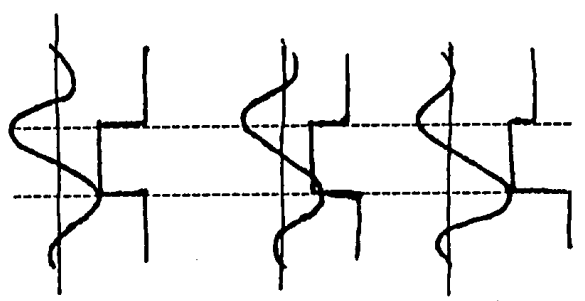

270 degrees 0 degrees 90 degrees
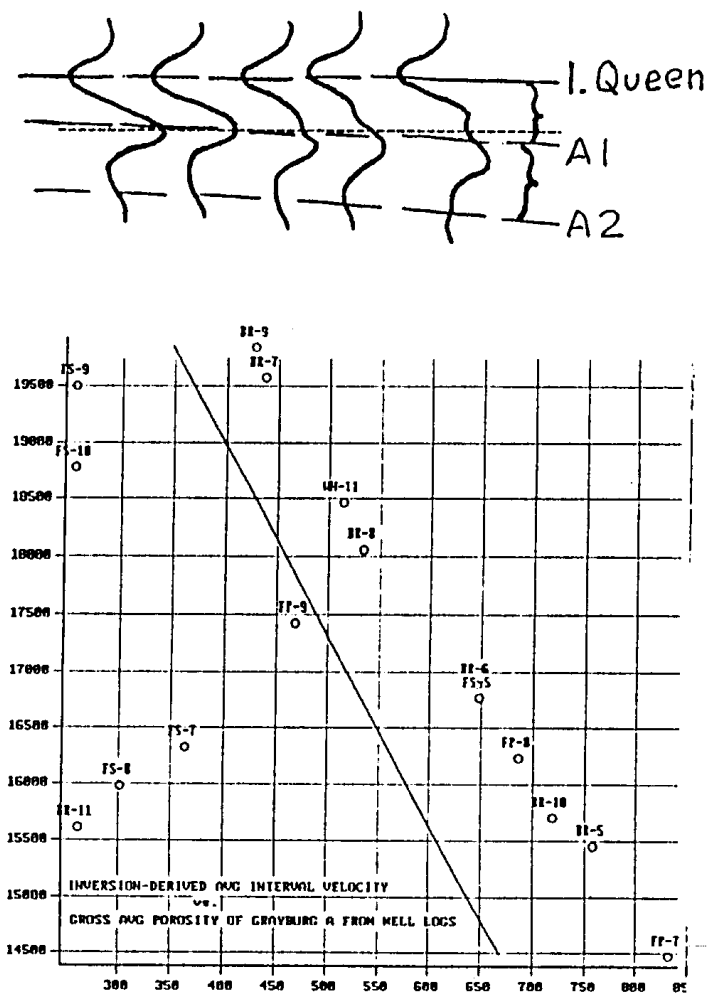
Review:

The seismic inversion model created in December, 1996, was the result of normal parameter testing and produced a high correlation relationship of the inversion-derived average interval velocity cross-plotted with gross average porosity of the Grayburg A zone from well log measurements. The top of the A zone was defined by revising the reflection surface mapped as the Grayburg. The re-picking was made using the profile view of the inversion data, placing the pick at the low-to-high velocity interface (lower Queen - Grayburg). The pick coincides with the top of the $A$ in section 36 , where the rock property data used in the cross-plots are located. However, in section 31 the $A$ is not the first carbonate below the lower Queen marker and does not coincide with top of the Grayburg. The bottom of the A interval was picked $10 \mathrm{~ms}$ below the A horizon.

Unfortunately, the cross-plots of those parameters for the B, C, and San Andres zones show no strong relationships. The $B$ interval was defined as the zone 10$13 \mathrm{~ms}$ beneath the $A$, and the $C$ interval was the $7 \mathrm{~ms}$ zone below the $B$. In order to improve those relationships the model would have to be refined and the boundaries of the production intervals would have to be accurately defined.

The analysis of the Grayburg A zone was described in the previous report, but will be summarized here for continuity. A strong, linear relationship exists on the cross-plot of the inversion-derived average interval velocity versus gross average porosity. Using 20 modern well logs, values for the gross average porosity were charted (Fig. 1). Of those values 15 fit the cross-plot line and 6 well values fall off the line, with too-low measured velocity values. A map of the distribution of A zone porosity was made using the cross-plot relationship. This porosity distribution was used in a reservoir simulation model for the Grayburg A zone.

Work during the quarter:

Improving the inversion model itself involves testing other seismic parameter choices and more precisely identifying wavelet phase. Listed here are the user input parameters which affect the inversion model and have been extensively tested:

Horizons - are located by tracking a peak or trough associated with an impedance contrast definable in geologic terms to position velocity constraint values; modeling results show that the reflections may not coincide with lithologic boundaries, as presumed

Velocity Constraints - are values of velocity determined from sonic logs, used to control inversion model trace values; minimum and maximum values set a range which represents geologic possibilities within each stratigraphic sequence being modeled (Fig. 2) 
Amplitude - is a relationship of the processed seismic data with a synthetic seismogram

Bandwidth - is an approximation of wavelet bandwidth across the volume $(X, Y$, and $T)$ of amplitude data to be inverted

Phase - is a variable which strongly affects the velocity values of the inversion trace and is a function of the input data rather than being a test parameter (see example on the preceding page)

Modifications to the preliminary inversion model input parameters involved the constraints of horizon position and velocity values. The lower Queen reflection is a consistent lithologic boundary and was retained. The "Grayburg" reflection is a composite reflection which does not resolve the top of the A zone, but is used to set the velocity at the top of the Grayburg sequence. The reflection near the San Andres may result from rock property changes near the interface since no continuous lithologic boundaries exist between the lower Grayburg and the San Andres. For this reason, the San Andres constraint is not handled as a lithologic boundary. Constraint values are needed below the top of the San Andres, but reflections are discontinuous because of structural and stratigraphic complexity. The Holt, a carbonate unit near the base of the San Andres, has been picked in addition to the Glorieta, an uppermost Clearfork clastic unit, to constrain velocities within the San Andres.

Phase shifts of 45 and 315 degrees were applied to the data, creating new, independent data volumes, for input to the model computation. Different models result from each phase shifted input data set. The significance of the differences is expected to be recognized by cross-plot correlations and the correct phase will result in a maximum correlation. Models have been made with each phase shifted input. Analyses of the A zone have been made and do show anticipated differences. Work is still ongoing to develop a model which will satisfactorily describe rock properties of each Grayburg zone (A, B, C-D, E-F-G-H) and the upper San Andres.

Analysis of an inversion model across very specific zones requires accurate positioning of zone boundaries. For this project, only the first of several zones of interest, the Grayburg A1, is defined by a seismic reflection event, and then only approximately because of limited resolution. The engineering model requirements demand the thinnest intervals possible to be measured and mapped. The thinnest mapped intervals of production are the Grayburg $A$, subdivided into A1 ( $\sim 70$ feet) and the A2 ( $\sim 50$ feet), the Grayburg B, subdivided into B1 ( $\sim 50$ feet) and the B2 ( $\sim 50$ feet), and the Grayburg C ( $\sim 30$ feet). Determination of quantitative characteristics of these geologic intervals from observations of seismic waveform is futile. The inversion model describes vertical sequence intervals on the order of $5 \mathrm{~ms}$ (40-50 feet) thick, which might represent the true seismic resolution. If this conclusion is correct, analyses of those thin intervals are meaningful. 
Establishment of analysis boundaries for the preliminary analysis are based on an interval of Grayburg A zone assumed to be $10 \mathrm{~ms}$ thick. This is a reasonable, but general estimate which works in section 36 , but is not adequate just off structure in section 31 where that sequence thickens. In addition, the B and C and the San Andres boundaries are not defined in any way by mapable seismic events and must be set some other way. A series of isopach maps (exemplified in Figs. 3, 4, 5) was made showing the thickness of the subdivided Grayburg zones. These maps have been used to predict an accurate position for each log call equivalent boundary by converting thickness in feet to time in milliseconds. Summing the four Grayburg intervals that were calculated results in a San Andres surface which is close to the reflection initially picked as the San Andres.

\section{Work in Progress:}

The most successful test model traces made since the initial model have visually (qualitatively) very good comparative relationship to sonic logs in relative velocity curve shape and display surprisingly high resolution. Progressive, small changes in the model parameters are being made to preserve the success of the preliminary model and to improve upon it. The objective of the optimized model is to have high cross-plot correlations of inversion-derived velocity and wellborederived porosity for all productive zones.

\section{GEOLOGY}

\section{Witcher \#12 Core and Completion}

The core analysis for the lower Grayburg and San Andres core taken in the Witcher \#12 (Fig. 6) was completed this quarter. As noted in the report for fourth quarter 1996, there were three zones of visible porosity in the San Andres portion of the core. The core analysis verifies that these zones are indeed porous but relatively impermeable. The deepest zone (Fig. 7), between 43454362 feet, has 9 feet of greater than $9.5 \%$ porosity, with permeabilities ranging from .67 to $5.01 \mathrm{mD}$. The middle zone ( $4316-4342$ feet) has 18 feet of greater than $8.4 \%$ porosity, with permeabilities ranging from .78 to $14.74 \mathrm{mD}$ with most in the range of $2.5 \mathrm{mD}$ to $5.0 \mathrm{mD}$. The upper porosity zone in the San Andres (42734312 feet), has 11 feet of greater than $7.7 \%$ porosity; the permeabilities range from .7 to $1.3 \mathrm{mD}$.

Because whole core analysis takes from one month to six weeks to complete, it was decided to perforate and acidize the upper two zones in the San Andres to determine their potential producability based on visual inspection of the core and log analysis. Initially, the upper two porous zones in the San Andres were perforated and acid spotted. On swab test, the zones had very slow fluid entry and only about $10 \%$ oil cut (see ENGINEERING). 
Results of the acid stimulation of these two zones were confirmed by the core analyses. The upper zone has very low permeabilities due to anhydrite infilling and would require additional stimulation. Although the middle zone has better permeabilities, the geologic model proposed for the upper San Andres assumes significant areal variability and, therefore, the core permeabilities are not representative of the zone away from the well bore. The hypothesis is that subaerial exposure and fresh water diagenesis have significantly altered the San Andres reservoir. Evaluation of the slabbed core indicated the presence of fresh water diagenesis as deep as 95 feet below the top of San Andres. There are intervals with mudstone and wackestone collapse breccias encased in cavern filling massive anhydrite. These caverns are roofed and floored by porous grainstone and packstone intervals (the tested intervals), with only minor dissolution, and variable anhydrite infill. Other cavernous intervals are filled with very fine sand and silt which percolated down, and partially filled, solution enlarged vertical fractures in the vadose zone.

Log analysis of the San Andres would lead to the conclusion that both of the tested intervals were porous $(8-18 \%)$ and should be productive. Neither zone is commercially productive without fracture stimulation. The $5-10 \%$ of secondary porosity cannot be contacted without a larger fracture stimulation. Although the porous grainstone and packstone intervals locally have excellent porosity and permeability, they have become compartmentalized during fresh water diagenesis. Anhydrite pore infilling during burial has also reduced overall permeability.

\section{Water Analyses}

Analyses of produced water analyses has become the standard method in the study area to determine if water production is from the San Andres or the lower Grayburg. Enough isolated water samples have been recovered to distinguish waters by their Sodium (Na), Chloride (Cl), and Total Dissolved Solids (TDS). Waters with TDS's of 60,000 to 64,000ppm are San Andres in origin and waters with TDS's from 36,000 to 42,000ppm are lower Grayburg in origin (Fig. 8).

The Witcher \#12 produced water sampled two weeks after the lower Grayburg completion, indicated the water is almost entirely San Andres (60,000ppm TDS). As the fracture completion was designed to frac the lower Grayburg and frac down into the San Andres, this was expected.

The Foster \#11 produced water has been sampled a number of times this quarter and the analyses indicate a steady increase in the San Andres component in the water. This was not anticipated as the perforations and fracture treatment were designed to stay above the San Andres in the lower Grayburg. The one produced water sample collected from the Witcher \#2 indicates the water is almost entirely from the lower Grayburg. This was both designed for and hoped for. 
Water sampling and analyses on both producing and injection wells will continue. All producing wells and injection water stations were sampled in May, 1996. All the wells and injection stations will be resampled this next quarter to provide a base line.

\section{ENGINEERING}

\section{Simulation}

Quantitative integration of the seismic data into the reservoir simulation continued this quarter. Initial modeling analyses of $A$ and $B$ zone porosity maps are encouraging. The objective is to history match the old waterflood and use the validated model to optimize the current waterflood by recompleting existing wells and drilling new wells. This is an iterative process which integrates geophysics, log analysis and reservoir simulation and it is not expected that the current maps will be the final ones.

\section{Reservoir Engineering}

The Witcher \#12 (Fig. 7) was drilled at the end of 1996 with completion in 1997. Initially the two uppermost of three porosity zones in the San Andres were tested (see GEOLOGY). The middle zone (4316-4342 feet) was tested first; perforated from $4318-4330$ feet and acidized with 1200 gals $15 \%$ NEFE acid. The zone swabbed dry in two hours, with entry rates thereafter of 400 feet of fluid per hour with $15 \%$ oil cut. The uppermost zone, from $4275-4287$ feet, was then perforated and acidized with 1850 gals $15 \%$ NEFE acid. This zone swabbed dry in $11 / 4$ hours, thereafter entry rates of 500 feet of fluid per hour with a $10 \%$ oil cut were determined. These entry rates would not have resulted in a commercially successful well without additional stimulation. Because of the potential for water encroachment from the zone below 4375 feet, it was decided not to fracture stimulate the San Andres zones alone.

Because of the previous failures to successfully fracture stimulate the San Andres without producing large volumes of water, a different methodology had to be applied. It was decided to fracture stimulate a porous interval in the lower Grayburg, with the anticipation that the frac height of a "normal" frac would be sufficient to reach down to the productive intervals in the San Andres but not far enough to communicate with the water bearing interval below 4375 feet. The lower Grayburg was perforated and fraced. Production during February and March showed a severe decline as the well pumped off. A pressure buildup test is scheduled and will be reported on next quarter. The water analyses (see GEOLOGY) indicates that most of the produced water is from the San Andres. At the end of the quarter, production was 35BO, 303BW, and 10MCFGPD. 
The Witcher \#2 was recompleted from the San Andres to the lower Grayburg this quarter. The reason the Witcher \#2 was recompleted was that the San Andres production had decreased from $70 \mathrm{BO}, 225 \mathrm{BW}$, and $18 \mathrm{MCF}$ to $4 \mathrm{BO}, 32 \mathrm{BW}$, and $2 \mathrm{MCF}$ in seven months. A "Pipeline Frac", was utilized in an attempt to stay "in zone" in the lower Grayburg and not fracture down into the San Andres. The Pipeline Frac attempts to pump a gel with no sand to initially break the formation, followed by a different gel carrying sand which "fingers through" the first gel. This "fingering through" has been demonstrated to be successful at producing maximum depth of penetration into the formation without producing large fracture height.

The well was put on pump at the end of the first quarter and has not yet stabilized. Fluid level is still high. A pressure buildup test is scheduled and will be reported on next quarter. Initial production rates are encouraging.

The Foster-Pegues \#4 was converted to injection, averaging 125BWPD at 723 psig surface pressure. This is the first well to go on injection with the benefit of clean injection water. The injection profile showed all the water was entering the $A$ zone in the upper Grayburg with none entering the lower Grayburg. Both the injection rate and the injectivity profile are disappointing considering the high quality of the injection water. A pressure fall off test was run to further diagnose the problems with this well. The test showed that the well was still storage dominated after 15 days of shut in and had an anomalously high storage coefficient. This indicates a mechanical problem which will be evaluated.

\section{Water Quality}

Continued work on the quality of the injection water has resulted in dramatic improvements in water quality. Further injection well work can now proceed with the objective of waterflood sweep improvement.

\section{Acknowledgments}

We would like to acknowledge James J. Reeves and Hoxie W. Smith for conceiving and managing the DOE study and for being responsible for the geophysical study. We would like to acknowledge that, since April, 1996, William C. Robinson has been responsible for the reprocessing and reinterpreting the seismic data and for the geophysical study. Also since that date, Robert C. Trentham has been responsible for project management. 


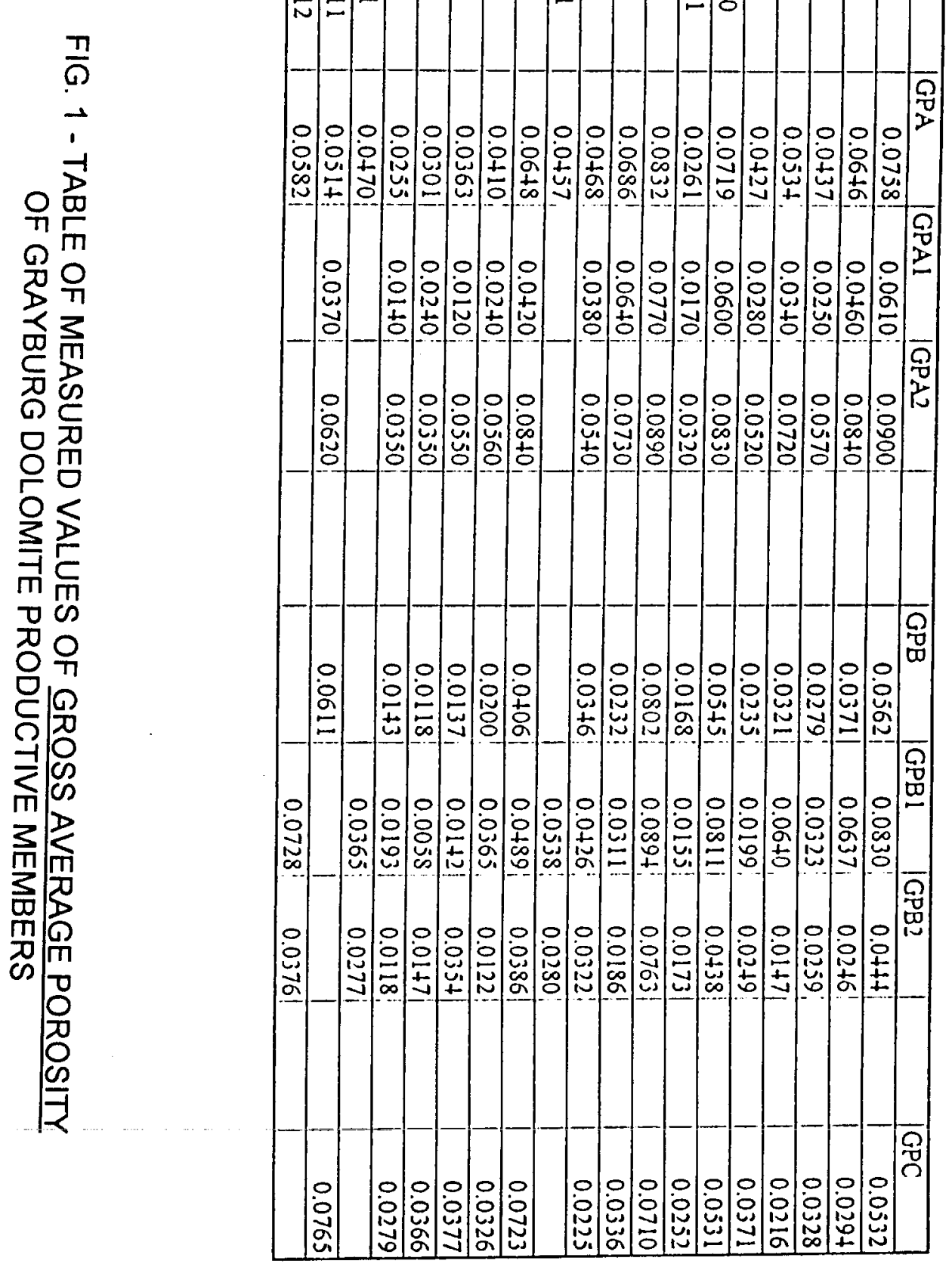




\begin{tabular}{|c|c|c|c|c|c|c|c|c|}
\hline MODEL NAME: DOE 0313.IMD & 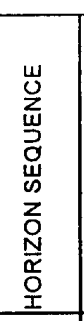 & 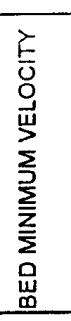 & 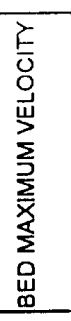 & 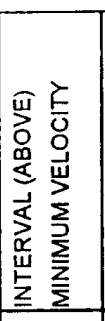 & 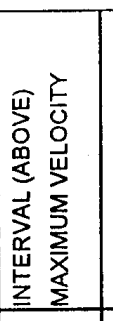 & 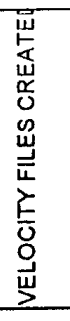 & 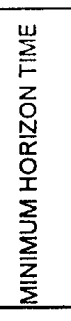 & 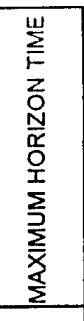 \\
\hline $\begin{array}{l}\text { HORIZON FILE } \\
\text { DATA RANGE IL: I-74 TR: } 121 \\
\text { TOP OF MODEL (ms) }\end{array}$ & 400 & & & & & & & \\
\hline YATES & & $10^{\circ}$ & $12^{5}$ & $11^{5}$ & $17^{\circ}$ & $10^{\circ}$ & 500 & 590 \\
\hline QUEEN & & $12^{5}$ & $13^{5}$ & $9^{0}$ & $16^{5}$ & & & \\
\hline LOWER QUEEN & & $12^{5}$ & $14^{\circ}$ & $12^{\circ}$ & $17^{\circ}$ & $\begin{array}{l}11^{5} \\
12^{0}\end{array}$ & & \\
\hline GRAYBURG & & $15^{\circ}$ & $20^{\circ}$ & $12^{5}$ & $18^{\circ}$ & $\begin{array}{l}13^{0} \\
13^{5} \\
14^{0}\end{array}$ & 660 & 770 \\
\hline SAN ANDRES & & & $21^{\circ}$ & $15^{\circ}$ & $22^{\circ}$ & $15^{\circ}$ & & \\
\hline HOLT & & $18^{\circ}$ & $20^{\circ}$ & $12^{\circ}$ & $21^{\circ}$ & $\begin{array}{l}16^{5} \\
17^{\circ}\end{array}$ & 780 & 1020 \\
\hline TIME TO RUN & & & & & & $\begin{array}{l}21^{\circ} \\
22^{\circ}\end{array}$ & & \\
\hline LAST WINDOW & & $15^{\circ}$ & $20^{\circ}$ & $12^{0}$ & $21^{\circ}$ & & & \\
\hline MODEL END (ms) & 1250 & & & & & & & \\
\hline BAND PASS FREQUENCIES & $8-12-85$ & -100 & & & & & & \\
\hline
\end{tabular}

SCALE FACTOR 50K

FIG. 2 - AN EXAMPLE OF INVERSION CONSTRAINT VELOCITIES ASSOCIATED WITH CONSTRAINT HORIZONS 


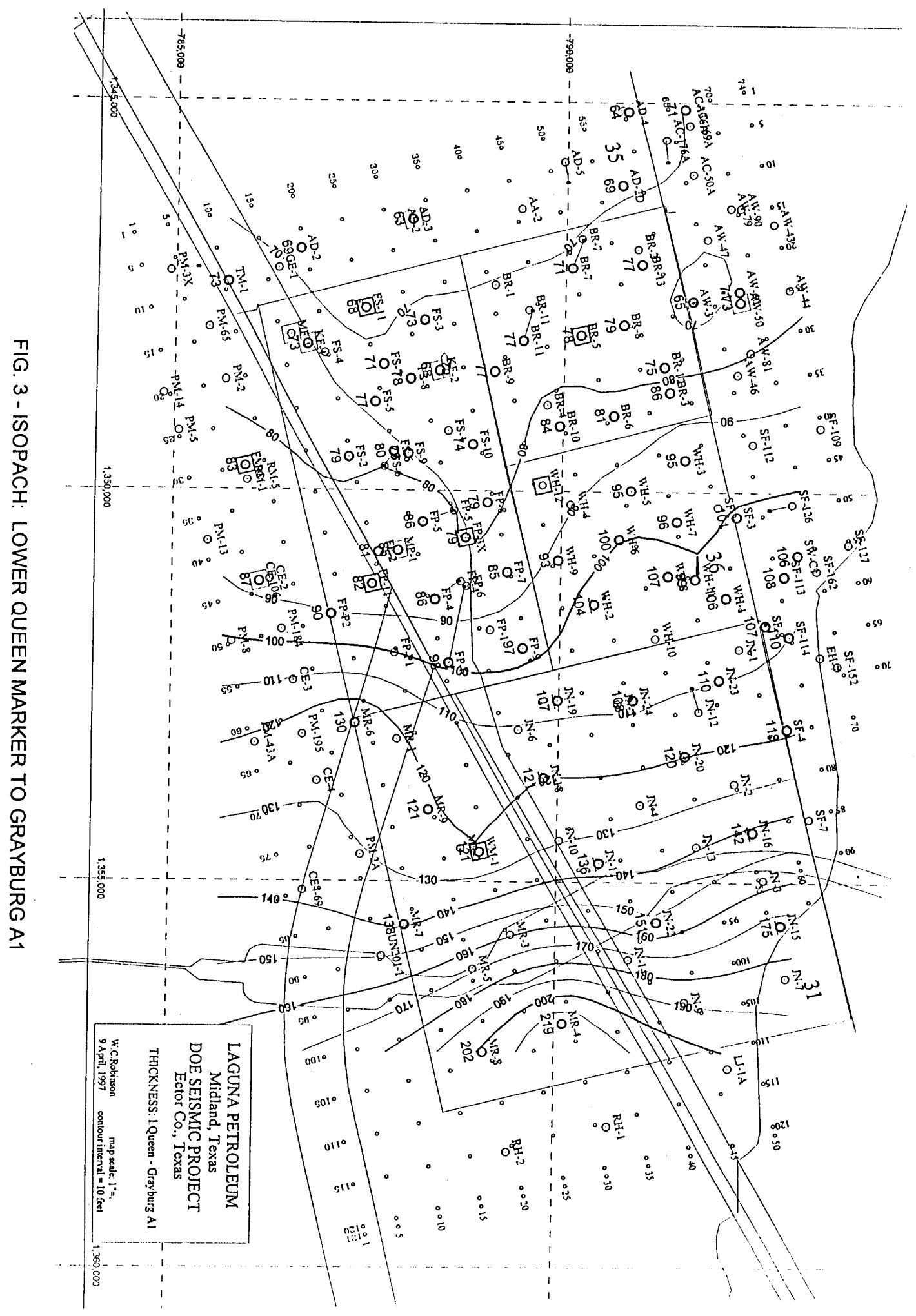




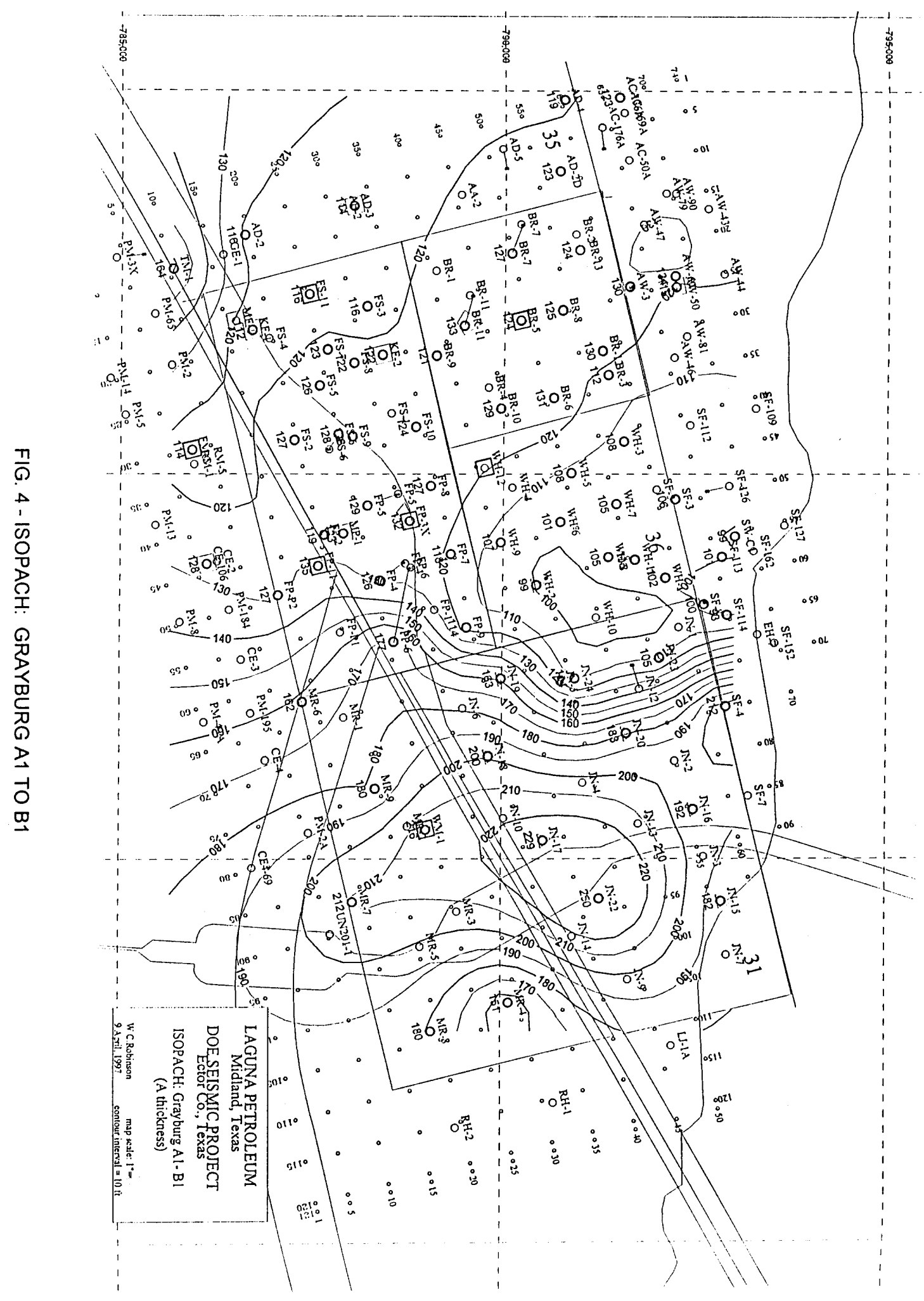




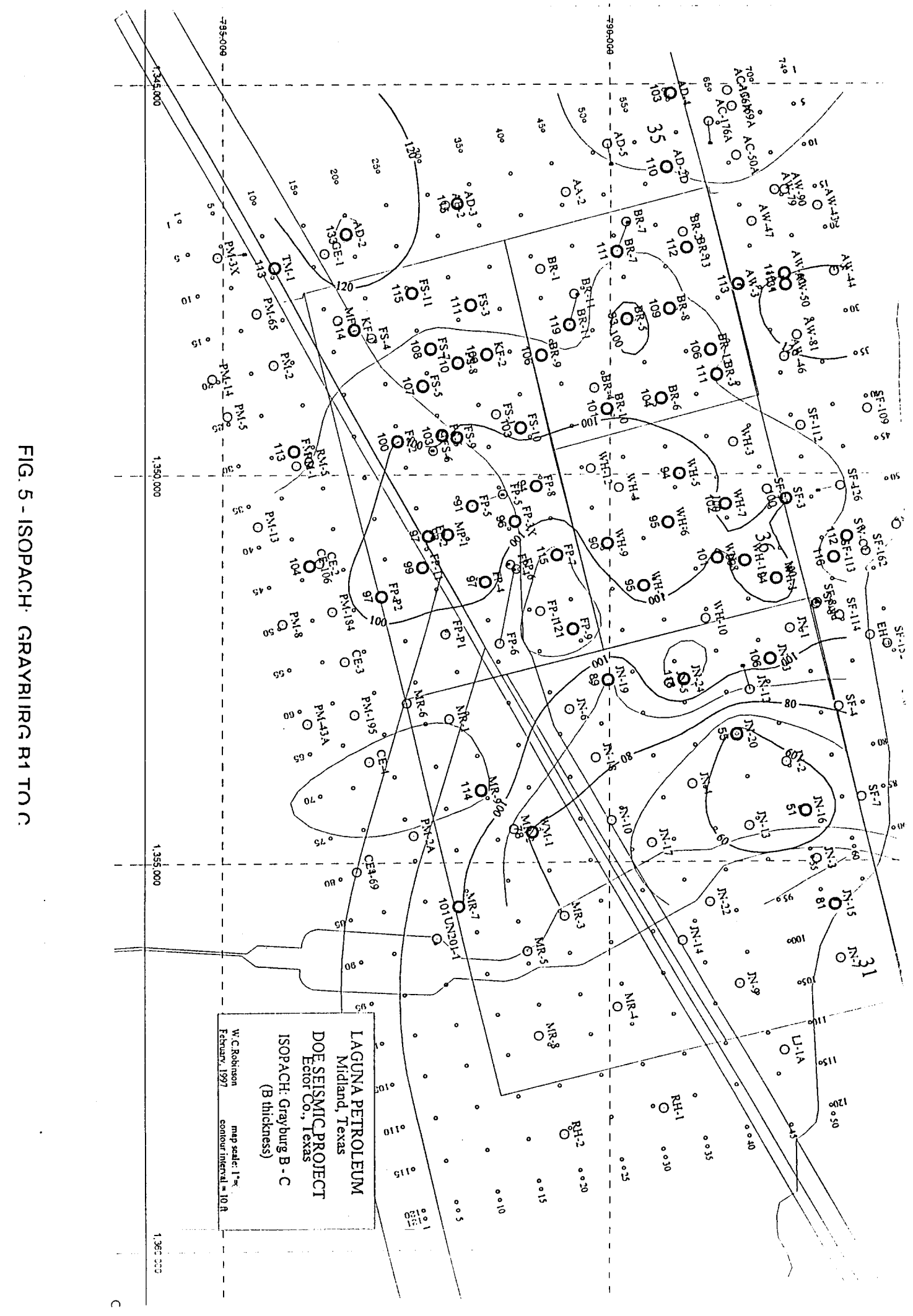




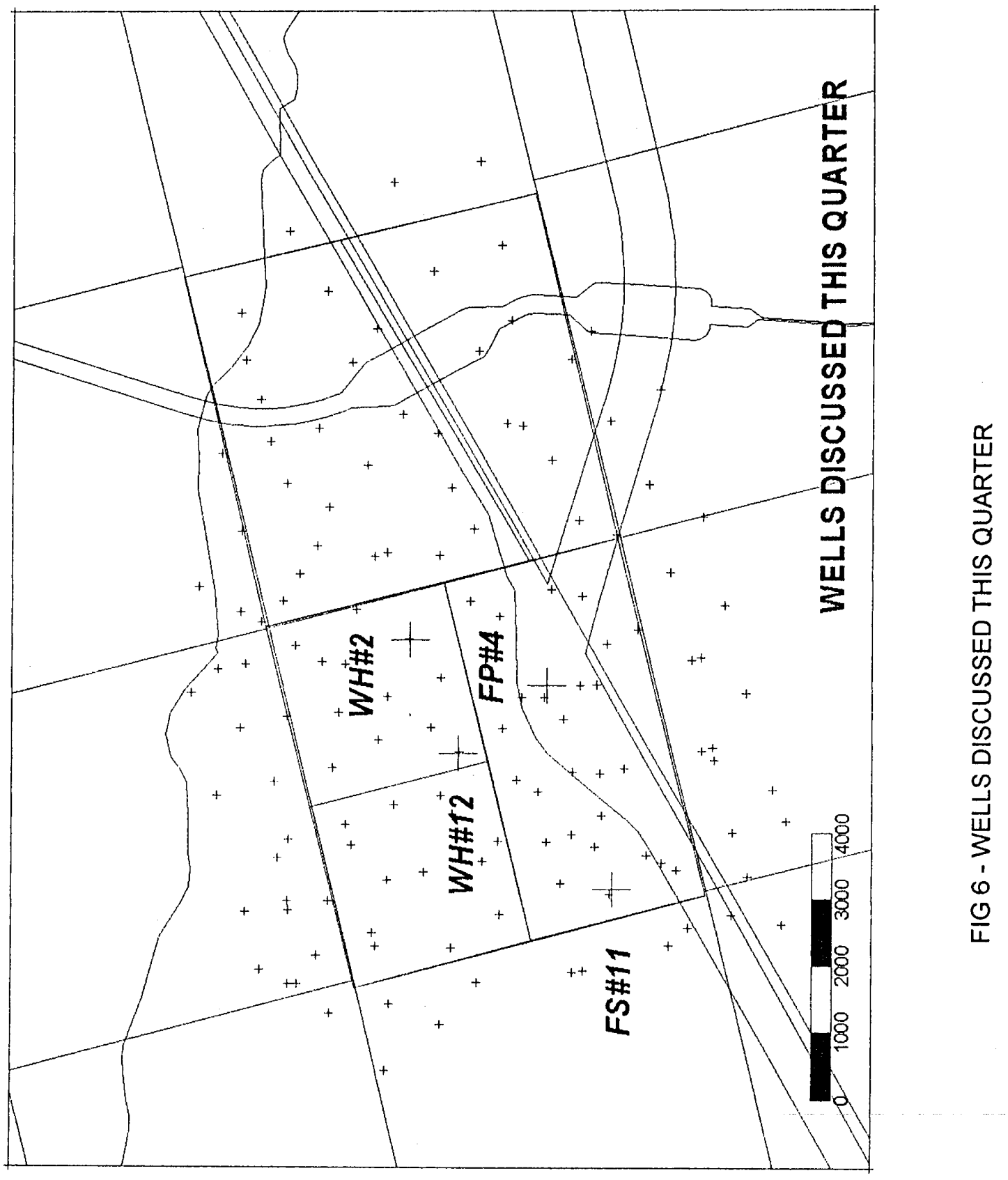




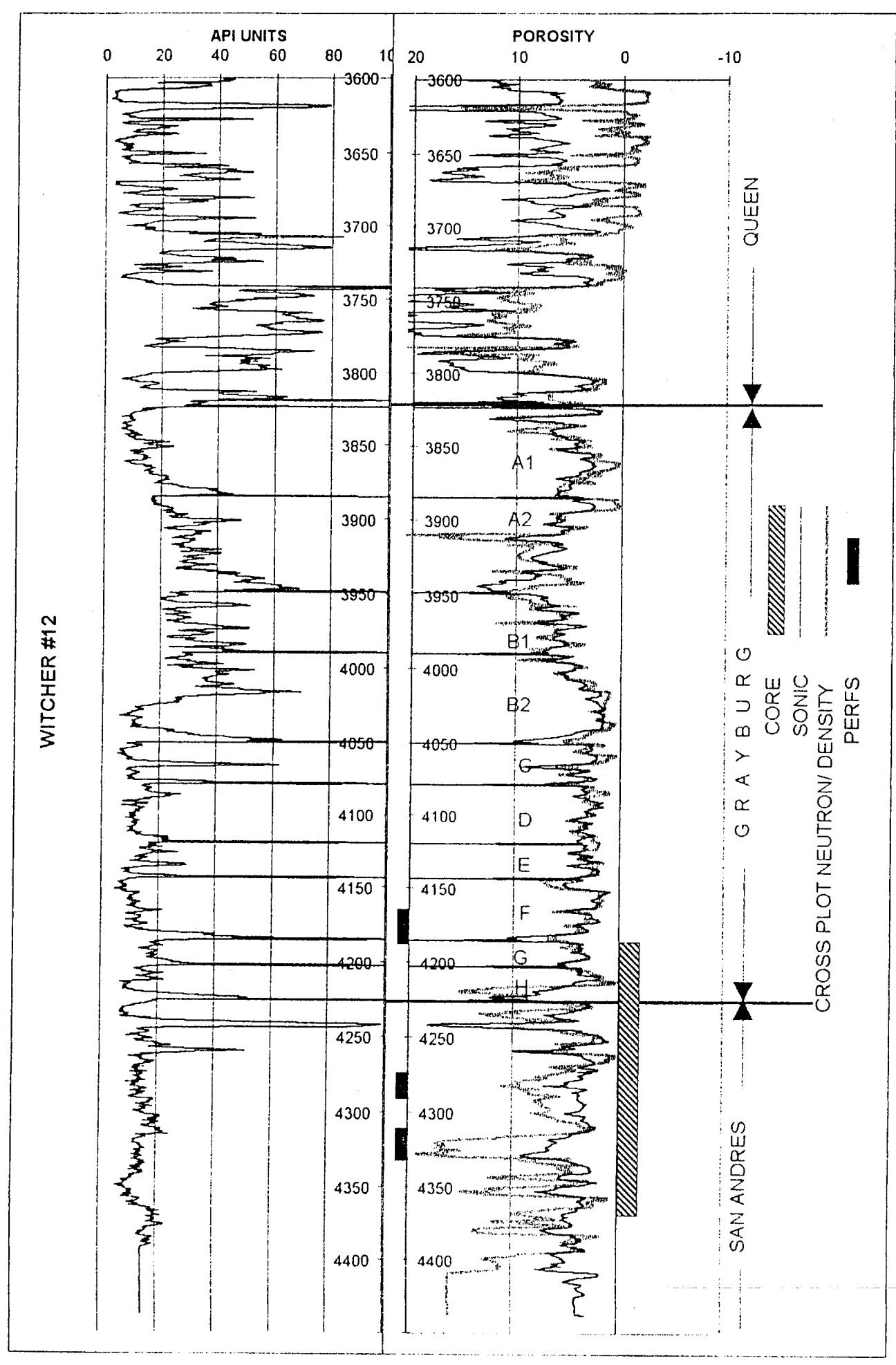

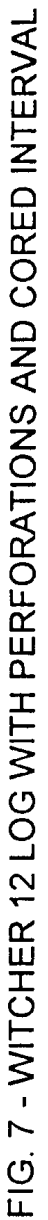




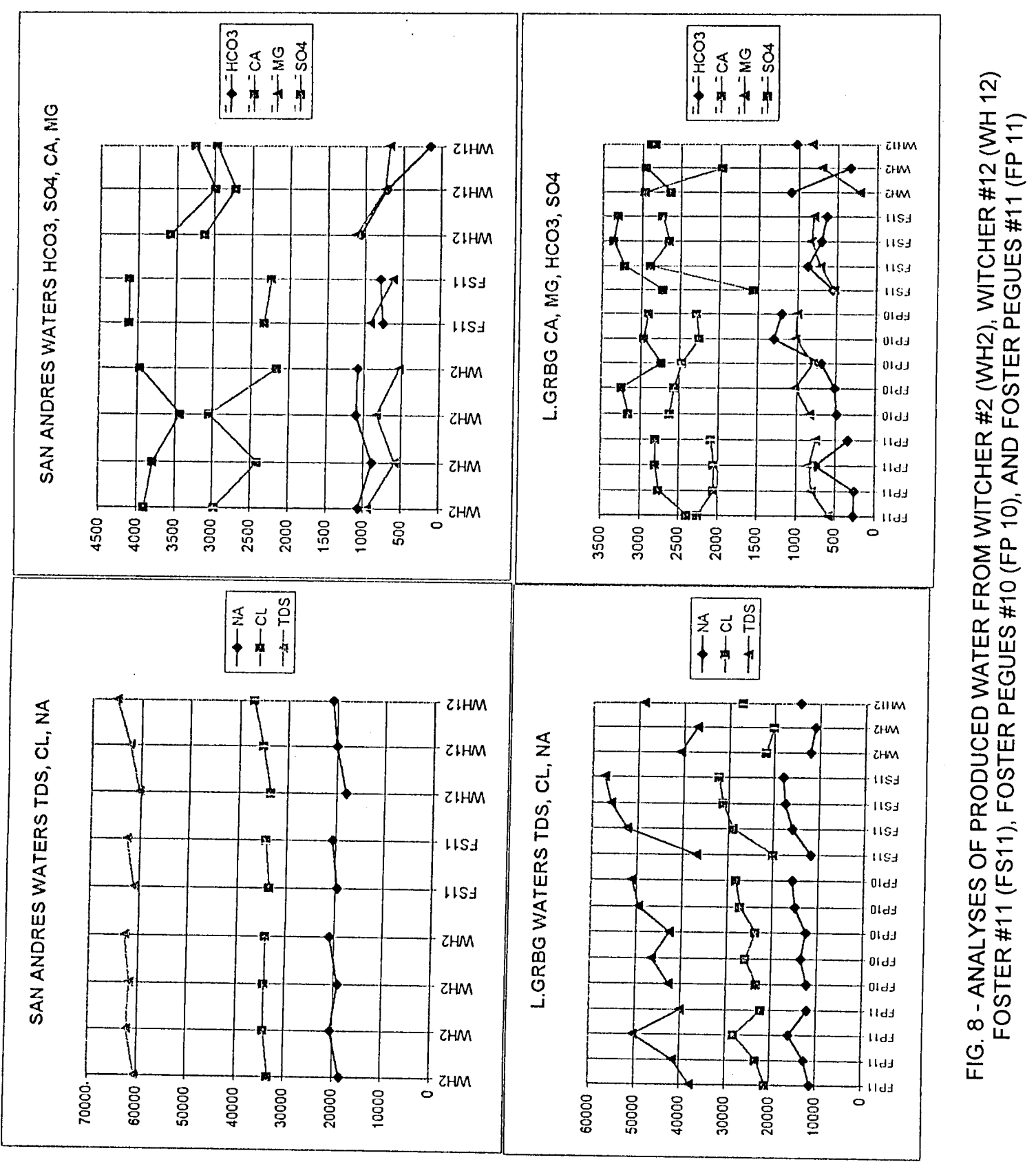

